\title{
Design of dual system teaching management system based on.Net Technology
}

\author{
Liang $\mathrm{HU}^{1, \mathrm{a}}$ \\ ${ }^{1}$ Jiangxi Science \& Technology Normal University, Nanchang, Jiangxi, 330013, P.R. China
}

\begin{abstract}
With college enrollment, the number of students continues to soar, significantly increasing the difficulty of teaching management. In the highly developed network of information technology today, how to achieve through modern information technology and efficient integration of network information resources, in order to achieve continuous improvement of the level of education, teaching and simplify management and reduce the human and financial investment, the university has become common Follow hot topic. Based on this, on a systematic and structural design of the .NET technology teaching management system based on a research point, the system through ADO.NET technology to access educational information and database retrieval, XML technology to achieve rights management, Finally, this system functions realization more thorough discussion. This system is used for the teaching management mode of German dual system localization, has a good effect
\end{abstract}

Key words: Dual system, XML, ADO.net, localization

\section{Introduction}

Today, the information age, based on the construction of information management system has become an important indicator of the level of teaching in Colleges and universities [1]. Teaching management system is the core of the construction of digital university. This kind of system can through modern information technology integration teaching resources, realize the sharing of resources, to provide a new and effective teaching platform for teachers and students, and optimize teaching resources investment, simplifying the task of teaching management. The following paper on a systematic and structural design of .NET technology-based education management system started to explore and implement this function of the system is analyzed.

\section{Significance of Teaching Management System Design}

Based on .net technology education management system is at the same time as the students and teachers to serve students in this system, through online technology, access to educational resources, courseware, learning and other auxiliary materials. Teachers are teaching in the system management module, the content of student information, teaching arrangements query and management, and through the campus network, publishing important information and teaching courseware, network instruction, etc. [2]. Thus, based on .NET technology while teaching management system can provide teachers and teaching management services, not only to provide network information management and teaching for teachers, but also be able to provide students with an efficient education resource sharing learning platform.

\section{System design of teaching management}

\subsection{System Architecture Design}

The learning management system access via ADO.NET technology and the transfer of educational information database to XML technology to achieve rights management, system design hierarchy, users can log in through a browser, the background provided by the WEB system and network database service support, the specific structure as shown below.

\footnotetext{
a Corresponding author: 596325696@qq.com
} 


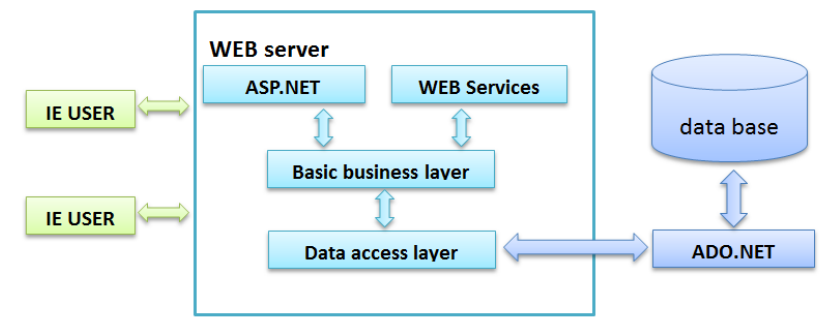

Figure 1. Schematic diagram of the structure of teaching management system based on.Net Technology

\subsection{Function of the system design of each module}

System also teachers and students as clients, according to the different needs of teachers and students teaching management, resource management module is divided into teaching, basic management module, user management module and switch modules and other teaching resources.

\subsubsection{The function of education resource management module design}

The main function modules include the preparation, revision, upload, review, revise teaching resources and so on.

Teaching Resources Upload: Teacher by logging in the client module to operate various types of teaching resources, storage and uploading.

Teaching resource sharing and download: teachers and students can be found teaching resources have been uploaded in the system, after registration, and free downloads.

Teaching Resources Audit: Before the formal uploading, you need to review the teaching staff responsible for evaluation, after passing the examination before officially uploaded.

Teaching Resources inquiry: teachers and students can be queried by entering the keyword, the system will enter keywords related resources with a display of all out, teachers and students can select from teaching resources they need to be viewed or downloaded.

Teaching Resources Delete: system administrator or upload resources educators can not meet the standards, or there is an error of teaching resources delete operation.

Teaching Resources Statistics and Analysis: The system of teaching resources Click to view the amount of downloads for automatic statistics, and ratings based on statistical results to help teachers and students selected the most valuable teaching resources.

\subsubsection{The basic function design system management module}

In this module can be serviced teaching management system, the system administrator and the system administrator privileges given to those who register before the landing module [3]. Key features include network configuration, fault repair, network information security, performance, maintenance, and other statistics and analysis. Also provided with extensible interface that enables the system to achieve system expansion and upgrade work through this interface.

\subsubsection{Function design of user management module}

Although to improve teaching quality, university teaching resources should share resources, but not all types of resources can be fully open, so as to achieve information security management, we need to set user permissions in this module. By the system management personnel, including teachers, students, auditors, unregistered persons (tourists) [4] set permissions. Such as registering students to teaching resources query, uploading, downloading and other operations, and teachers on the basis of students' rights, the courseware can be edited, modified, etc. operations. Tourists will only search and browse without downloading privileges.

\subsubsection{Teaching Resources switching module functional design}

Teaching Resources This module exchange is a resource sharing model, not a teaching resource management module campus resource sharing, but remote data exchange, sharing of resources between institutions at all levels. This module teaching resources in XML format for output, the system by means of information stored in the DOM XML format for access, then depending on the permissions of the user configure the menu, the process shown in Figure 2.

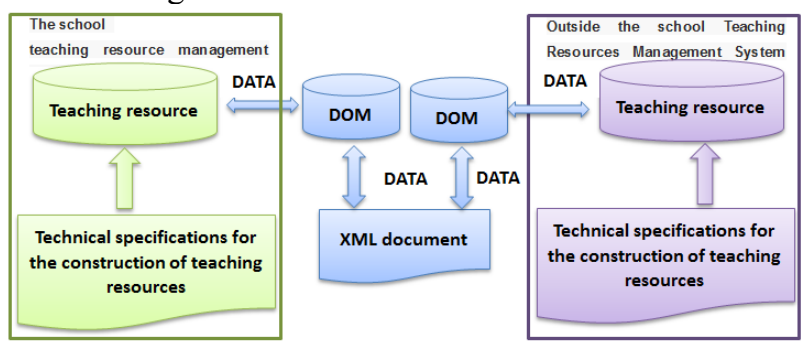

Figure 2. Data exchange process design of teaching resource exchange module

\section{Function of the system to achieve}

System is a hierarchical structure to achieve functional modules, divided into presentation logic, business logic, information layer.

\subsection{Implementation of a logical layer}

The presentation layer logic layer that is used to implement the interface between systems and the role of the user in the system, this logic layer mainly in the form of a dedicated web page rendering, customers and dialogue between programs in a dedicated web page, such as a user enter, log, etc., and feedback the corresponding results based on the user's actions. 


\subsection{The implementation of business logic layer}

This logic layer is the core of the whole system, the whole system is responsible for data processing. System to design and deliver the convergence between the common database and be responsible for each database, and then developed based on the operational process design two kinds of business logic components of the system, are VB.net technology, namely basic business management and business components, responsible for basic component business is for users to achieve system operation and function of the client implementation [5]. Another component is responsible for managing the business, that system administrators use component management system management is mainly achieved through this component.

\subsection{Implementation of information layer}

System information layer is mainly responsible for the management and analysis of information and data, and analysis results back to the business logic layer, and then implemented by the business logic feedback function [6]. The system management module teaching resources, teaching resources through the switching modules are required to implement an information layer functions operate more modules to run in the database layer ADO.net information technology to connect and access the database to interact with the data transfer, as well as NET technology systems through greatly enhanced the familiar data access, and storage process more flexible.

\section{Conclusion}

To sum up, this paper firstly analyzes the design significance of the teaching management system based on.Net technology, and then discusses the overall structure design of the system, on this basis, respectively of educational resources management module, system management module, user management module and teach learning resource exchange module function design are discussed. Finally, the said logic layer, business logic layer and information layer of the concrete implementation scheme are discussed, hope that this research can provide some reference for the stakeholders. This paper is the Achievements of Jiangxi Science and Technology Normal University Institute of Technical Education topics project that localization Practice Research of Germany dual system mode .

\section{References}

1. Li Jing, Zhang Jianhua. CD software and application of the design and research of [J]. ASP.NET technology in computer network teaching system based on 2014,20:295-296.

2. support, Fuchun rock, Xue Jiamei, Zhang Jingda, Guo Jiping, Ge Maosong, Liuyue, Qu Silong, Xiao Guang su. Based on. Net environment of the ordinary college undergraduate course teaching level evaluation management system design. Journal of Jiamusi University Journal (NATURAL SCIENCE EDITION), 2010,06: 894-896.
3. Yuan Hongjuan, Gu Sheng, Xu Yan. Based on XML and ASP. Net technology to achieve the teaching resource management system [J]. Xi'an University of Arts and Science (NATURAL SCIENCE EDITION) Journal. 2012,01:92-95.

4. Jia Wei Zhang, Longbin, Kan Jianxiong, Wang baijuan. Based on. Net technology class information management system design and implementation of wireless Internet technology [J]. And 2012,08:65-66.

5. Yang Chaohui, Wang Fang. And the implementation of $[\mathrm{J}]$. technology and business vocational college educational management system design based on ASP.NET technology, 2013,13:144.

6. Zhong $\mathrm{Wu} \mathrm{Li}$, Chen Jingrui, summer Chunmei. Based on. Net technology of Baoshan college online school management system design and implementation of computer in Fujian [J]. And 2013,11:40-41. 